\title{
Predicting Hygrothermal Behavior of an Underground Stone Chamber with 3-D Modeling to Restrain Water-Related Damage to Mural Paintings
}

\author{
Yonghui Li*1 ${ }^{1}$, Daisuke Ogura ${ }^{2}$, Shuichi Hokoi ${ }^{3}$, Jianguo Wang ${ }^{4}$ and Takeshi Ishizaki ${ }^{5}$ \\ ${ }^{1}$ Lecturer, Key Laboratory of Urban and Architectural Heritage Conservation of Ministry of Education, \\ School of Architecture, Southeast University, China \\ ${ }^{2}$ Associate Professor, Graduate School of Engineering, Kyoto University, Japan \\ ${ }^{3}$ Professor, Graduate School of Engineering, Kyoto University, Japan \\ ${ }^{4}$ Professor, School of Architecture, Southeast University, China \\ ${ }^{5}$ Deputy Director General, National Research Institute for Cultural Properties, Tokyo, Japan
}

\begin{abstract}
Cultural properties are variously influenced by their surrounding environmental conditions. One of the reasons for the deterioration of mural paintings in the Takamatsuzuka Tumulus was the humid microclimate on their surface. In order to control the deterioration of mural paintings caused by such problems, it is important to investigate the environmental factors from various aspects, such as the temperature, humidity, water content of cultural properties, wetting and drying cycles and so on. As for the research concerning hygrothermal behavior on mural paintings, these variables may not be thoroughly predicted by 1-D or 2-D for determination of the location and degree of the deterioration of mural paintings. This paper shows how a 3-D hygrothermal model developed with a view to analyzing the preservation measures that allow quantifying of the degree of drying and condensing processes occurred on the surfaces of the underground chamber. The findings show that for the purpose of preserving mural paintings within the underground chamber, the temperature difference between the surrounding mound and the protected object should be kept as constant as can be practically achieved. This method is applicable for estimating the effects of preservation measures for the conservation of other mural paintings.
\end{abstract}

Keywords: hygrothermal behavior; 3-D modeling; condensation; dryness; water-related damage; Takamatsuzuka Tumulus

\section{Introduction}

There are many important mural paintings in underground chambers in Asian countries. Among them, the underground stone chamber of the Takamatsuzuka Tumulus is well known for its beautiful paintings. The tumulus was discovered on 21 March 1972 in Asuka village (N: 34.47, E: 135.82), Nara Prefecture, Japan. The tumulus is a circular mound with a diameter of $19 \mathrm{~m}$ and height of $5 \mathrm{~m}$ (Fig.1.(a)). The stone chamber, which is $1.03 \mathrm{~m}$ wide, $1.13 \mathrm{~m}$ high, and $2.65 \mathrm{~m}$ deep, is buried within a mound of soil about $3 \mathrm{~m}$ below ground level. The mural paintings were designated as national treasures in 1974 and a committee of specialists was organized for their conservation. After extensive discussion, the committee

*Contact Author: Yonghui Li, Dr. Eng., Lecturer,

Key Laboratory of Urban and Architectural Heritage Conservation of Ministry of Education, Southeast University,

Si Pai-Lou 2\#, Nanjing, 210096, China

Tel/Fax: +86-25-83790530

E-mail: liyonghui@seu.edu.cn; ogurad@archi.kyoto-u.ac.jp

(Received October 2, 2013 ; accepted March 11, 2014) decided to preserve the mural paintings at the site. For this purpose, a climate chamber and conservation facilities were constructed in 1976 in order to keep the mural paintings under the same conditions as when they were found. During the period from the discovery of the mural paintings in 1972 to the beginning of the operation of the conservation facility in 1976, an emergency preservation measure including a temporary shelter erected on the south side of the tumulus (see Fig.1.(b)) was adopted to control the hygrothermal environment in the stone chamber. Then, because of the difficulties in preserving the mural paintings onsite, the stone chamber was dismantled (from October 2006 to August 2007) to restore the paintings in temporary restoration facilities.

In recent years, Asian scholars have begun to pay more and more attention to the research of cultural heritage protection ${ }^{1), 2), 3), 4)}$. The conservation of mural paintings in natural underground sites is difficult. As we all know, the deterioration factors are all greatly influenced by hygrothermal behavior surrounding the mural paintings. High temperature, humid air and condensation near such paintings will accelerate 
the risk of biological attack ${ }^{5), 6), 7), 8)}$, and wetting and drying cycles inside the chamber greatly increase the risk of physical and chemical deterioration ${ }^{9)}$, such as detachment of lime plaster from the wall surface, salt deposition, etc. In order to restrain deterioration of mural paintings caused by such problems, it is important to investigate environmental factors from various aspects, such as temperature, humidity, the water content of cultural properties, wetting and drying cycles and so on.

The case study of Takamatsuzuka Tumulus has been described by previous papers with $1-\mathrm{D}^{9)}$ or $2-\mathrm{D}^{10), 11)}$ numerical analysis, and the effects of post-excavation preservation measures on the hygrothermal behavior of Takamatsuzuka Tumulus was analyzed ${ }^{10)}$. However, as for the research of hygrothermal behavior on the surface of the mural paintings, these variables may not be thoroughly predicted by $1-\mathrm{D}$ or $2-\mathrm{D}$ for the determination of the location and the degree of the deterioration of mural paintings, and a suitable design method to prevent deterioration has not yet been established. The purpose of this paper is to review the case study of the Takamatsuzuka Tumulus by using a 3-D hygrothermal model, identify the impact of the hygrothermal environment on the deterioration of mural paintings in the underground stone chamber, as well as propose a favorable design method of preservation measures for the conservation of mural paintings based on the measured temperature, humidity inside the chamber, and the material characteristics.

\section{Model Description and Methods 2.1 Object}

Fig.1. shows the temporary conservation facilities during and at the end of the excavation in 1972 . About two weeks after the excavation, the south part of the stone chamber was exposed to the outside. Subsequently, a temporary conservation facility, connecting the front of the stone chamber, was erected to maintain the environmental conditions of the south part of the chamber as the same as those prior to its exposure. Soil and a waterproof sheet were applied to cover the south part of the chamber, except for the investigation area inside the stone chamber. The model (Fig.2.) shows a 3-D illustration with the surrounding mound according to the measured size of the Takamatsuzuka Tumulus ${ }^{12)}$. The excavated area filled with soil in Fig.2. is the state prior to excavation, while the excavated area exposed to the air refers to the state immediately after the excavation without any conservation measures. First, the authors analyzed the hygrothermal behavior in the stone chamber when the preservation measures were applied immediately after excavation, namely, a temporary shelter $(2.75 \mathrm{~m}$ in width, $7.5 \mathrm{~m}$ in length, and $4.5 \mathrm{~m}$ in height) with a plastic corrugated roof erected in front of the excavated area. The exposed southern part of the chamber was covered with soil and a waterproof sheet as shown in
Fig.3., from April 1972 to December 1975.

\subsection{Equations}

In this paper, the basic analytical equation is a coupled heat and moisture transfer equation, referred to as Matsumoto M'model ${ }^{13), 14)}$ and shown in Eqs. (1) and (2), which are based on heat and moisture movement in porous materials.

$$
\begin{aligned}
& \text { Heat: } \quad(c \rho)_{a p} \frac{\partial T}{\partial t}=\nabla \cdot\left[\left(\lambda+r \lambda_{T g}^{\prime}\right) \nabla T+r \lambda_{\mu g}^{\prime} \nabla \mu\right] \\
& \text { Moisture: } \rho_{w} \frac{\partial \psi}{\partial \mu} \frac{\partial \mu}{\partial t}=\nabla \cdot\left[\lambda_{\mu}^{\prime}(\nabla \mu-g \mathbf{n})+\lambda_{T}^{\prime} \nabla T\right]
\end{aligned}
$$

Here, $(c \rho)_{a p}$ is the apparent heat capacity of the material $\left[\mathrm{J} / \mathrm{m}^{3} \mathrm{~K}\right], T$ is temperature $[\mathrm{K}], \lambda$ is thermal conductivity $[\mathrm{W} / \mathrm{m} \mathrm{K}], \lambda_{\mu g}^{\prime}$ is moisture conductivity related to water chemical potential gradient (gas phase) $[\mathrm{kg} / \mathrm{ms}(\mathrm{J} / \mathrm{kg})], \lambda_{T g}^{\prime}$ is moisture conductivity related to temperature gradient (gas phase) $[\mathrm{kg} / \mathrm{ms}$ $\mathrm{K}], \rho_{w}$ is density of liquid water $\left[\mathrm{kg} / \mathrm{m}^{3}\right], \mu$ is water chemical potential $[\mathrm{J} / \mathrm{kg}], \psi$ is volumetric moisture

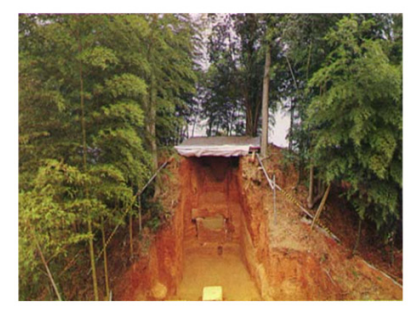

a) The excavation state

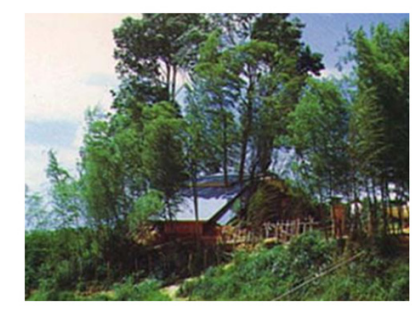

b) The state at the end of excavation
Fig.1. The Excavation State and the End State of the Excavation

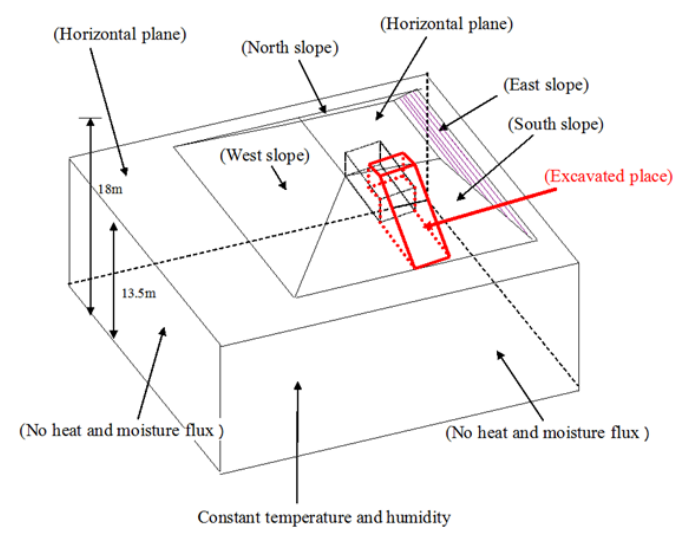

Fig.2. Model of the Excavation State

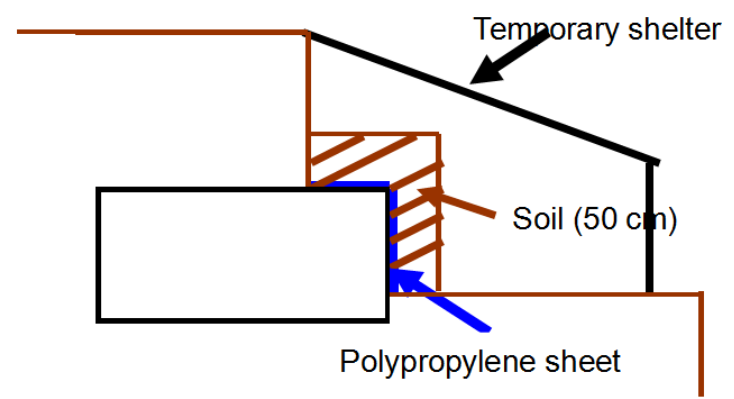

Fig.3. Model of the Excavation State and Diagram of Preservation Measures after Excavation 
content $\left[\mathrm{m}^{3} / \mathrm{m}^{3}\right], g$ is gravity acceleration $\left(9.8\left[\mathrm{~m} / \mathrm{s}^{2}\right]\right)$, $\lambda_{\mu}^{\prime}$ is moisture conductivity related to water chemical potential gradient $[\mathrm{kg} / \mathrm{m} \mathrm{s} \mathrm{J} / \mathrm{kg})], \lambda_{T}^{\prime}$ is moisture conductivity related to temperature gradient $[\mathrm{kg} / \mathrm{m} \mathrm{s} \mathrm{K}]$.

From this point, a series of subscripts and superscripts will be used in the equations. Their meanings are: subscript $j$ is the surface of the soil, $o$ is outdoor, (subscript $r$ is in the stone chamber), subscript Sat stands for Saturated, subscript $l$ is Moisture in the liquid phase, subscript $g$ is moisture in the gas phase, subscript $b$ is the temporary shelter, subscript $s$ is the surface in contact with the air, superscript $b i$ is inside surface of the temporary shelter, superscript bo is outside surface of the temporary shelter, superscript $b s$ is ground surface in contact with the air in the temporary shelter.

The relationship between water chemical potential $\mu$ and water vapor pressure $\mathrm{p}$ is as follows:

$$
\mu=R_{v} T \ln \left(p / p_{\text {sat }}\right)
$$

Here, $R_{v}$ is the universal gas constant for water vapor $\left[\mathrm{Pa} \mathrm{m}^{3} / \mathrm{kg} \mathrm{K}\right], P$ is the water vapor pressure $[\mathrm{Pa}]$.

The ground surface of the surrounding mound is treated as a bare area without considering the adjacent bamboo forest. Combining temperature and water chemical potential, the heat and moisture flux on the boundary of the bare ground surface is as follows:

$$
\text { Heat: } \begin{aligned}
&\left(\alpha+r \alpha_{T}^{\prime}\right)\left(T_{o}-T_{s}\right)+r \alpha_{\mu}^{\prime}\left(\mu_{o}-\mu_{s}\right)+q_{s o t}+q_{n o c} \\
&=-\left(\lambda+r \lambda_{T_{s}}^{\prime}\right) \frac{\partial T}{\partial n}\left|-r \lambda_{\mu s}^{\prime} \frac{\partial \mu}{\partial n}\right|,
\end{aligned}
$$

$$
\text { Moisture: } \quad \alpha_{\mu}^{\prime}\left(\mu_{o}-\mu_{s}\right)+\alpha_{T}^{\prime}\left(T_{o}-T_{s}\right)+J_{s}=-\lambda_{\mu}^{\prime}\left(\left.\frac{\partial \mu}{\partial n}\right|_{s}-g \mathbf{n}_{j}\right)-\left.\lambda_{T}^{\prime} \frac{\partial T}{\partial n}\right|_{s}
$$

Here, $\alpha$ is heat transfer coefficient $\left[\mathrm{W} / \mathrm{m}^{2} \mathrm{~K}\right], r$ is heat of gas/liquid phase change $[\mathrm{J} / \mathrm{kg}], \alpha_{T}^{\prime}$ is moisture transfer coefficient related to temperature gradient $[\mathrm{kg} /$ $\left.\mathrm{m}^{2} / \mathrm{s} \mathrm{K}\right], \alpha_{\mu}^{\prime}$ is moisture transfer coefficient related to water chemical potential gradient $\left[\mathrm{kg} / \mathrm{m}^{2} / \mathrm{s}(\mathrm{J} / \mathrm{kg})\right], q_{\text {sol }}$ is solar radiation $\left[\mathrm{W} / \mathrm{m}^{2}\right], q_{\text {noc }}$ is nocturnal radiation $[\mathrm{W} /$ $\left.\mathrm{m}^{2}\right], J$ is rainfall $\left[\mathrm{kg} / \mathrm{m}^{2} / \mathrm{s}\right]$.

The heat and moisture flux on the boundary of the surface of the inner walls of the stone chamber is expressed as follows:

$$
\text { Heat: } \begin{aligned}
\left(\alpha+r \alpha_{T}^{\prime}\right)\left(T_{r}-T_{s}\right)+r \alpha_{\mu}^{\prime}\left(\mu_{r}-\mu_{s}\right) & =-\left.\left(\lambda+r \lambda_{T_{g}}^{\prime}\right) \frac{\partial T}{\partial n}\right|_{s}-\left.r \lambda_{\mu \frac{3}{\partial}}^{\prime} \frac{\partial \mu}{\partial n}\right|_{s}
\end{aligned}
$$

Moisture: $\quad \alpha_{\mu}^{\prime}\left(\mu_{r}-\mu_{s}\right)+\alpha_{T}^{\prime}\left(T_{r}-T_{s}\right)=-\lambda_{\mu}^{\prime}\left(\left.\frac{\partial \mu}{\partial n}\right|_{s}-g \mathbf{n}_{j}\right)-\left.\lambda_{T}^{\prime} \frac{\partial T}{\partial n}\right|_{s}(7)$

The heat boundary condition of the inside surface of the temporary shelter is as follows:

$$
\alpha\left(T_{b}-T^{b i}\right)=-\lambda_{b} \frac{\partial T}{\partial x}
$$

The heat boundary condition of the outside surface of the temporary shelter is as follows:

$$
\alpha\left(T_{o}-T^{b o}\right)+q_{n o c}+q_{s o l}=-\lambda_{b} \frac{\partial T}{\partial x}
$$

For the air in the stone chamber, heat and moisture balance equations are applied, in which one particle indicates indoor air, as shown in (10) and (11):

$$
\begin{aligned}
& \text { Heat: } \alpha\left(T_{o}-T^{b o}\right)+q_{n o c}+q_{s o l}=-\lambda_{b} \frac{\partial T}{\partial x} \\
& \text { Moisture: } c^{\prime} V_{r} \frac{\partial p_{r}}{\partial t}=\sum_{j=1}^{m !} S_{j} \alpha_{m j}^{\prime}\left(p_{j}-p_{r}\right)+c^{\prime} V_{r} N_{r}\left(p_{b}-p_{r}\right)
\end{aligned}
$$

Here, $c \gamma$ is the volumetric heat capacity of air $[\mathrm{J} /$ $\left.\mathrm{m}^{3} \mathrm{~K}\right], \alpha_{m}$ is the moisture transfer coefficient $\left[\mathrm{kg} / \mathrm{m}^{2} /\right.$ $\mathrm{s} P a], S$ is the area of the wall surface $\left[\mathrm{m}^{2}\right], V$ is the air volume in the stone chamber $\left[\mathrm{m}^{3}\right], N$ is air change rate $[1 / \mathrm{s}], c^{\prime}$ is the moisture capacity of air $\left[\mathrm{kg} / \mathrm{m}^{3} \mathrm{~Pa}\right]$.

For the air in the temporary shelter, heat and moisture balance equations are applied, in which one particle indicates indoor air; however, since the wall of the shelter is damp proof, only heat behavior is considered. The equations are as follows:

$$
\text { Heat: } \begin{aligned}
c \gamma V_{b} \frac{\partial T_{b}}{\partial t}= & \sum_{j=1}^{m 2} S^{b s} \alpha_{j}\left(T^{b s}-T_{b}\right)+\sum_{j=1}^{m 3} S^{b i} \alpha_{j}\left(T^{b i}{ }_{j}-T_{b}\right) \\
& +c \gamma V_{b} N_{b}\left(T_{o}-T_{b}\right)+c \gamma V_{r} N_{r}\left(T_{r}-T_{b}\right)
\end{aligned}
$$

$$
\text { Moisture: } \begin{aligned}
c^{\prime} V_{b} \frac{\partial p_{b}}{\partial t}= & \sum_{j=1}^{m 2} S^{b s} \alpha_{j i j}\left(p^{b s}{ }_{j}-p_{b}\right)+c^{\prime} V_{b} N_{b}\left(p_{o}-p_{b}\right) \\
& +c^{\prime} V_{r} N_{r}\left(p_{r}-p_{b}\right)
\end{aligned}
$$

\subsection{Method}

The stone chamber of Takamatsuzuka Tumulus consists of a single-layered tuff wall, approximately $0.6 \mathrm{~m}$ thick, which is surrounded by sandy clay loam. Researchers have measured or calculated the equilibrium moisture content ${ }^{15), 16)}$, moisture conductivity and thermal conductivity of the tuff and sandy clay loam of the Takamatsuzuka Tumulus ${ }^{17)}$, ${ }^{18), 19)}$. The detailed data used as the input for the model can be found in the author's previous paper ${ }^{10)}$. As the outdoor climate conditions, the authors use the data collected by Nara Local Meteorological Observatories $^{20)}$, from 1972 to 1975 , including external temperature, air relative humidity, global solar radiation, precipitation and nocturnal radiation. An explicit control volume method is adopted for the calculations with a time step of 30 seconds. In calculating the environmental conditions in the state of emergency preservation measures following the excavation of the mural paintings, the initial conditions of the model were determined by the relevant annual cycle data of the year prior to excavation. The conditions for the calculation of the period from March 6 to April 1 are shown in Fig.2. (the excavated place exposed to the air). The calculation of the period after April 1 was conducted according to preservation measures as shown in Fig.3. Fig.4. shows the region of calculations and the boundary conditions. Boundary conditions applied in the model for the ground level and the inner surfaces of the stone chamber are of the third period, i.e. after April 1. At the bottom of the calculation region, the boundary conditions refer to the first kind of boundary conditions (temperature is $14.6^{\circ} \mathrm{C}$ and water chemical potential is $-7 \mathrm{~J} / \mathrm{kg}$ ). In 
addition, the setting condition in the temporary shelter after excavation has been mentioned in the author's previous paper ${ }^{10)}$.

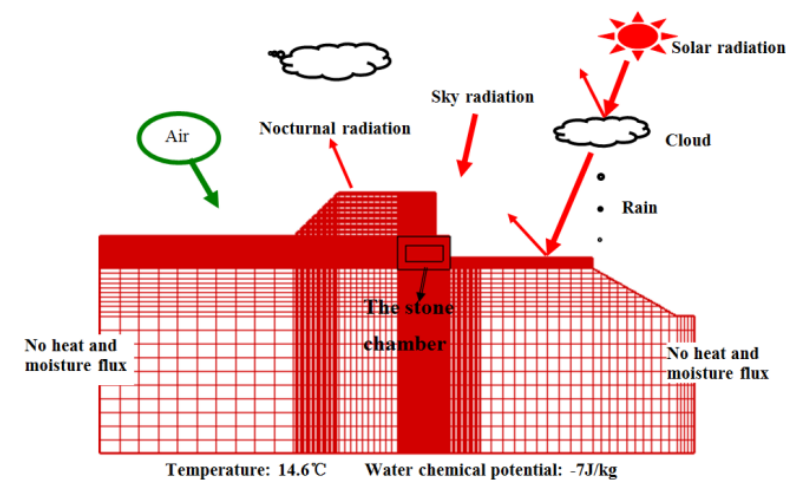

Fig.4. The Illustration of the Calculation Region and the Boundary Conditions

\section{Model Validation}

The analytical and measured values ${ }^{21)}$ of indoor temperatures from 1972 to 1973 are both indicated in Fig.5.(a). The results show that the calculated annual average and phase difference of the indoor temperature are in good agreement with the observed data, except for the annual amplitude where the calculated values are smaller than the measured ones. The measured temperature in the stone chamber is $13.6^{\circ} \mathrm{C} \pm 2.8^{\circ} \mathrm{C}$ (amplitude), while the calculated value is $13.5^{\circ} \mathrm{C}$ $\pm 2.5^{\circ} \mathrm{C}$ (amplitude). It is postulated that the threedimensional analytical model can reliably estimate the temperatures inside the stone chamber. As for humidity, the calculated value is as high as $99 \%$, as shown in Fig.5.(b), while the measured value is constant at $95 \% \mathrm{RH}$ (higher after opening the stone chamber for investigation). Considering the accuracy of the measuring instruments, the three-dimensional model is considered as reliable in estimating the relative humidity. The following section discusses the hygrothermal behavior in the underground stone chamber predicted by the model.

\section{Results of 3-D Model Calculations 4.1 The Degree of Drying of the Surfaces Inside the Chamber}

Fig.6. shows the temperature and moisture content distribution on the interior surfaces of the stone chamber at 12:00 a.m. on August 15, 1973. As shown in the figure, the temperatures of the south, east and west wall and its nearby ceiling are around $15.5^{\circ} \mathrm{C}$, whereas the temperatures of the north wall and its nearby ceiling, the east and the west walls as well as the floor are about $14.5^{\circ} \mathrm{C}$. The temperature difference on the interior surfaces of the stone chamber is about $1.0^{\circ} \mathrm{C}$ (Fig.6.(a)). The maximal temperature inside the chamber appears on the surface of the south wall and the nearby ceiling, and the water in those areas will likely undergo an evaporating process. At the same

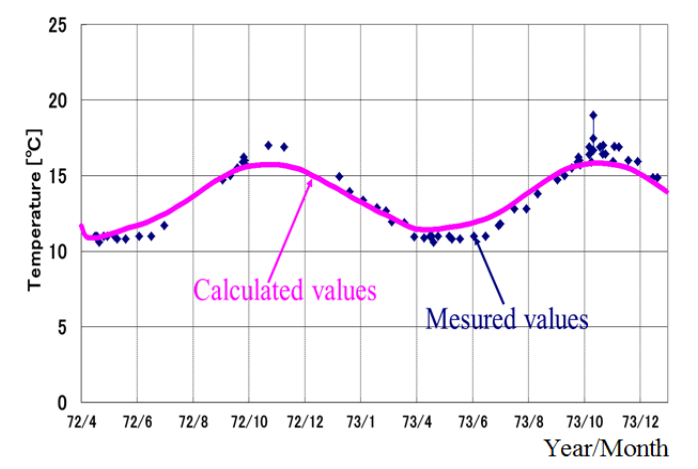

a) The calculated and measured temperatures of the stone chamber

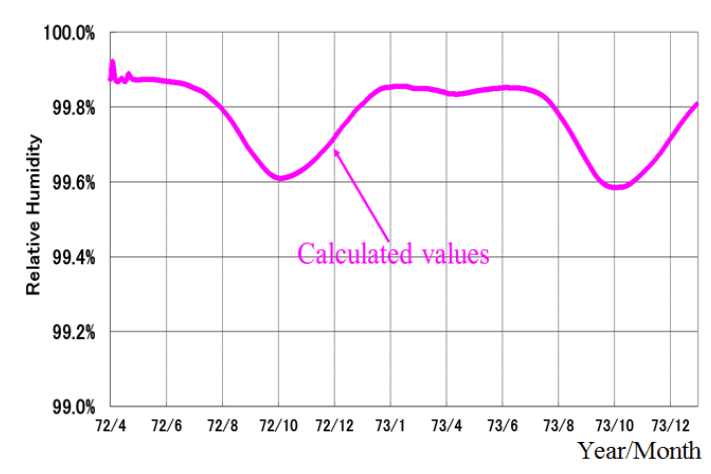

b) The calculated relative humidity in the stone chamber

Fig.5. Comparison between Calculated and Measured Temperature and Relative Humidity in the Stone Chamber

time, Fig.6.b) shows low moisture content on the inner surface of the south wall and the ceiling as well as both the east and west walls. Fig.6.(b) shows the lowest moisture content of the surfaces of the stone chamber, which is $0.14\left(\mathrm{~m}^{3} / \mathrm{m}^{3}\right)$ while the moisture content of other parts is $0.25\left(\mathrm{~m}^{3} / \mathrm{m}^{3}\right)$. This is due to the external air reaching the south wall and the nearby ceiling. In other words, the temperature of the exposed part of the chamber is higher than other parts during summer and lower in winter. Thus, the presence of external air causes a drying and wetting cycle throughout the year.

Fig.7. shows daily minimum moisture content on the surfaces inside the stone chamber during the period from 1972 to 1975 . The "daily minimum moisture content on the surface" is an index that reflects the extent of drying in the whole chamber. It can be seen from Fig.7. that the volumetric moisture content of interior surfaces in the chamber falls to $0.13\left(\mathrm{~m}^{3} / \mathrm{m}^{3}\right)$ and drops every year.

As mentioned above, repeated wet-dry cycles on the wall surfaces enhance the damage to the lime plaster layer. When the emergency preservation measures were used after the excavation, there was a risk of exfoliation of the mural paintings caused by dryness near the corner around the ceiling, the south wall of the chamber and a potential danger of water vapor condensation on the north side of the chamber. 


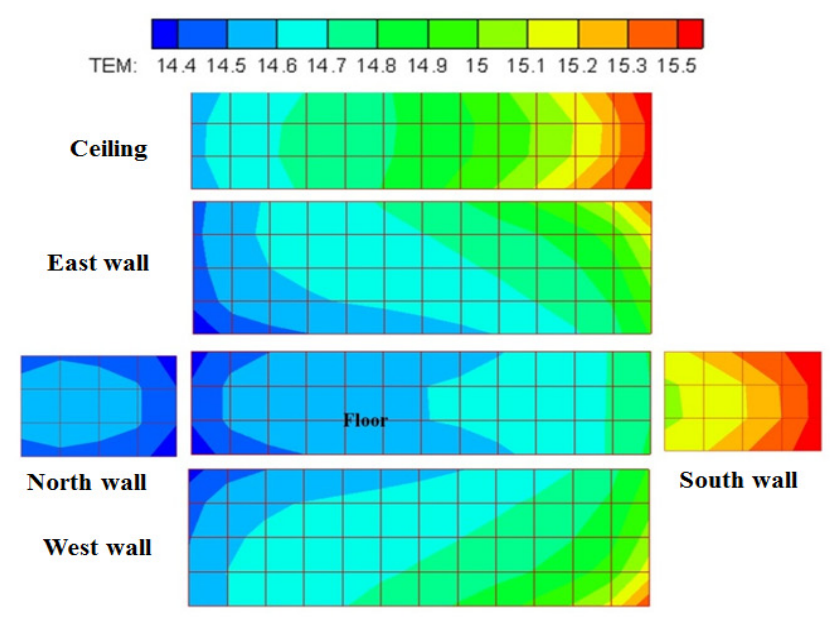

a) Temperature distribution on interior surfaces of the stone chamber

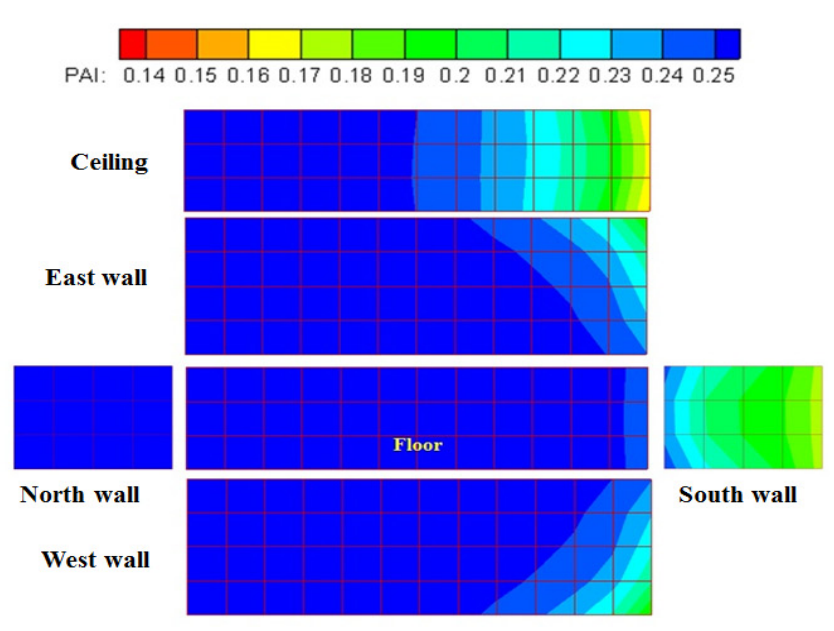

b) Moisture content distribution on interior surfaces of the stone chamber

Fig.6. Temperature and Moisture Content Distributions on Interior Surfaces of the Stone Chamber (12:00 a.m. August 15, 1973)

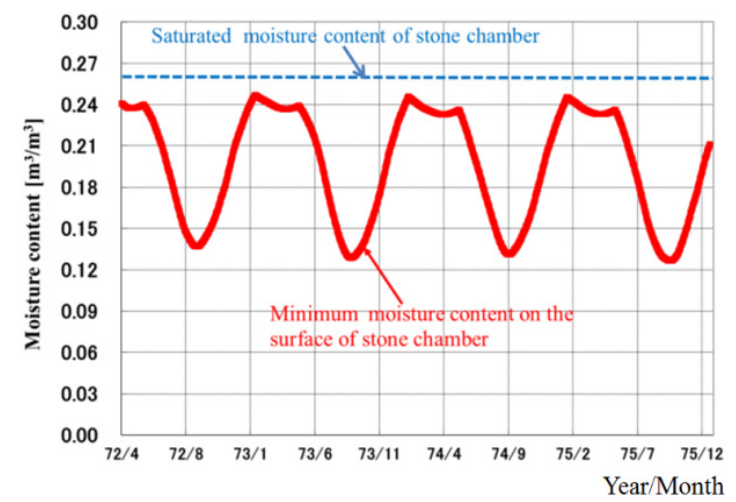

Fig.7. The Daily Minimum Moisture Content on the Interior Surfaces of the Stone Chamber from April 1972 to December 1975

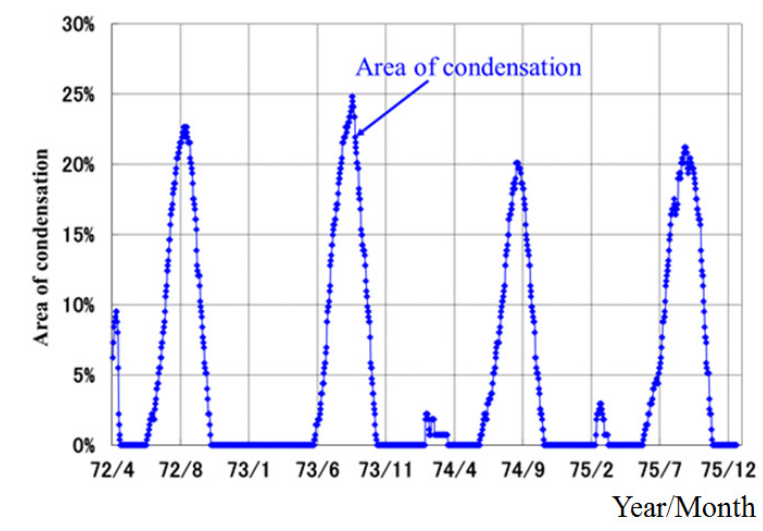

Fig.9. Condensation Occurred on the Interior Surfaces of the Stone Chamber from April 1972 to December 1975

\subsection{The Extent of Condensation on the Surfaces Inside the Chamber}

Fig.8. shows the condensation area on the interior surfaces and the number of condensation days during the year 1973. In this study, condensation is assumed to occur when the water chemical potential reaches $-5 \mathrm{~J} / \mathrm{kg}$

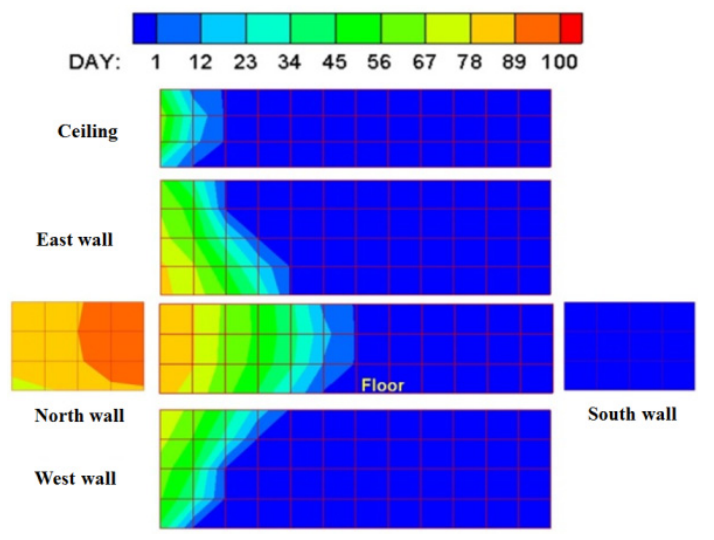

Fig.8. The Condensation Area and the Total Condensation Days Occurred on Interior Surfaces of the Stone Chamber (1973)

and the pore air is near $99.999 \% \mathrm{RH}$. This definition of condensation is only used to evaluate the risk of severe condensation. The "area of condensation" is the ratio of the condensation area to that of the total indoor surface area when such condensation occurs (Fig.8.). This condensation occurred on the north wall, the ceiling, the east wall, the west wall and the adjacent floor. In 1973, the days of condensation at the lower part of the north wall and its nearby floor were the highest, reaching 90 days or more.

Fig.9. shows the daily average of the area of dew condensation on the surfaces inside the stone chamber during the period from 1972 to 1975 . It can be seen that the area of condensation in the stone chamber increases from mid-June to the beginning of November. This is a seasonal occurrence every year with the maximum area of condensation reaching $25 \%$ of the area. From the perspective of control of biological attack, it is easy to accelerate the risk of such attack appearing in those areas. 


\section{Discussions}

5.1 Discussions on Adopted Preservation Methods after the Takamatsuzuka Tumulus was Excavated

When emergency preservation measures were adopted after the Takamatsuzuka Tumulus was excavated, the temperature control of the interior ambient did not solve the problems concerning the variation of hygrothermal conditions on the chamber surfaces. While the difference of the air temperature was small, the differences resulting from the interaction of thermal mass and the exposure conditions caused a wetting and drying cycle. From mid-June to the beginning of November, condensation occurred on the north wall side with its surrounding ceiling, the east wall, the west wall and the adjacent floor, while evaporation continued on the south wall. The computer model shows that, in the worst case scenario, the stone chamber will lose 50\% water content compared with the saturated condition, and in another worst case scenario, condensation will cover $25 \%$ of the area of the chamber. In other words, the drying and wetting cycle continues inside the chamber throughout the year. Fig.10. shows the temperature distribution of the horizontal section (central height of the chamber) of the Takamatsuzuka Tumulus on February 15, 1973 and August 15, 1973 respectively. In winter (Fig.10.(a)), the temperature of the south side of the surrounding mound of the stone chamber is lower than its north side. In summer, (Fig.10.(b)), the temperature of the south side of the surrounding mound of the stone chamber is higher than its counterpart. Fig.11. shows the maximum temperature difference of the whole stone chamber in 1973 . One can observe that the outside surface temperature is $5.4^{\circ} \mathrm{C}$ higher than the stone chamber in winter, and $7.2^{\circ} \mathrm{C}$ higher in summer. In other words, the emergency preservation measures produce wetting and drying cycles to the chamber, resulting in further deterioration of the mural paintings.

Considering the conservation of mural paintings in the underground chamber, one must ensure that the difference between summer and winter has a limited effect on the chamber conditions and maintain the indoor temperature in the chamber as low as possible to inhibit fungal growth.

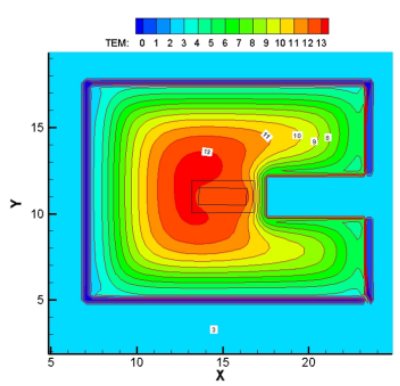

a) On p.m. 12:00, Feb. 15, 1973

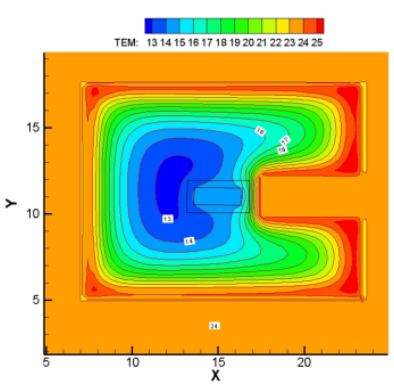

b) On p.m. 12:00, Aug. 15, 1973
Fig.10. The Temperature Distribution of the Horizontal Section (Central Height of the Chamber) of the Takamatsuzuka Tumulus

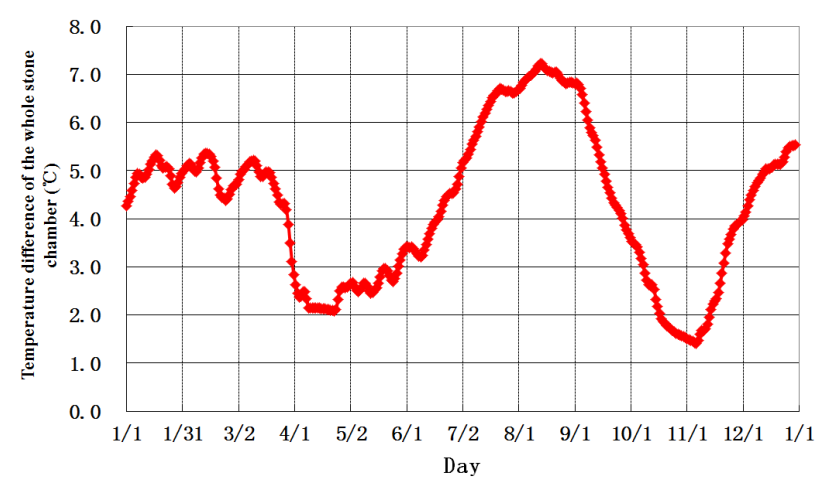

Fig.11. The Daily Maximum Temperature Difference of the Whole Stone Chamber in 1973

\subsection{Discussions on Suitable Preservation Methods}

Thermal insulation is applied to ensure the favorable preservation conditions postulated in the previous section. The shape and location of the thermal insulation layer is shown in Fig.12., with the increase of the thermal resistance of the covered insulation layer from $0.5\left[\mathrm{~m}^{2} \mathrm{~K} / \mathrm{W}\right]$ to $16.7\left[\mathrm{~m}^{2} \mathrm{~K} / \mathrm{W}\right]$. Fig. 13 . shows the annual maximum temperature difference of the whole stone chamber in 1973 in relation to thermal performance of the insulation layer (zero insulation representing the excavation state in 1972). It can be seen that the temperature difference becomes smaller as the resistance of the thermal insulation layer increases.

The authors further calculate the daily minimum moisture content and condensation area as shown in Fig.14. in relation to the temperature difference of the whole stone chamber compared with those shown in Fig.7. and Fig.9.

Fig. 14. shows the inverse relation between the growing temperature difference of the whole stone chamber and the descending minimum moisture content. Yet when the temperature difference is less than $4^{\circ} \mathrm{C}$, the area of condensation will become zero. This will happen when the thermal resistance of the covered insulation is about $7.0\left[\mathrm{~m}^{2} \mathrm{~K} / \mathrm{W}\right]$ (Fig.13.). Thus, favorable preservation of the mural paintings in the Takamatsuzuka Tumulus requires covering the exposed stone chamber by insulated material with thermal resistance of no less than $7.0\left[\mathrm{~m}^{2} \mathrm{~K} / \mathrm{W}\right]$.

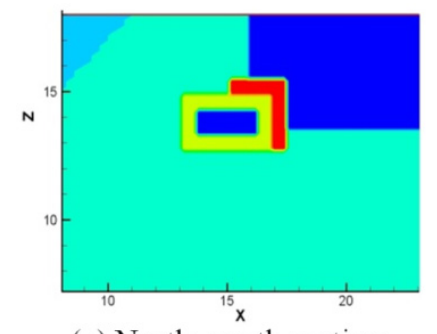

(a) North- south section

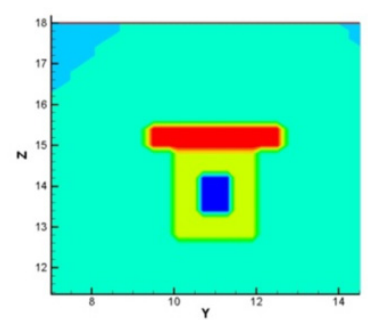

(b) East- west section
Fig. 12. The Position of Thermal Insulation Material in the 3-D Model (Red is the Thermal Insulation Material, and Yellow Represents the Stone Chamber) 


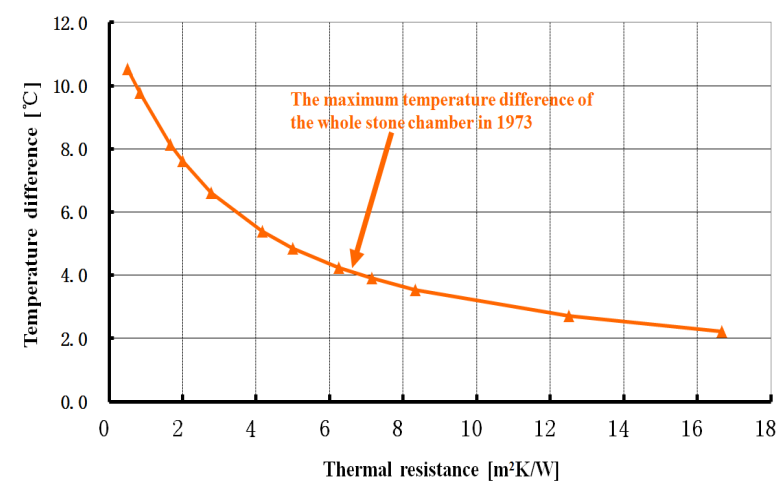

Fig.13. The Maximum Temperature Difference of the Whole Stone Chamber in 1973 when the Thermal Resistance of the Covered Material Changes

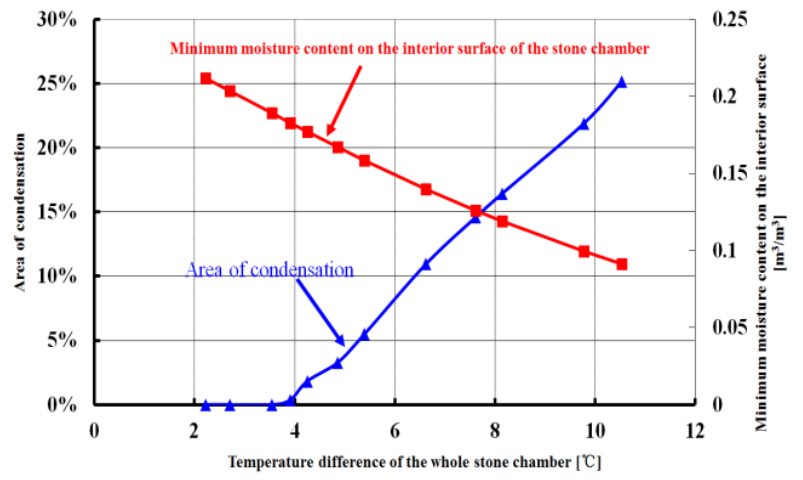

Fig.14. The Maximum Area of Condensation and Minimum Moisture Content on the Interior Surfaces of the Stone Chamber in 1973 when the Thermal Insulation Layer is Applied

\section{Conclusions}

This paper developed a 3-D model of the Takamatsuzuka Tumulus after excavation, based on the changed shape of the tumulus. The agreement between the measured and predicted values of air temperature and relative humidity in the stone chamber by $3-\mathrm{D}$ model was sufficient. The authors were therefore, able to use the 3-D model to predict the hygrothermal behavior of the underground stone chamber, and analyze the location and degree of water vapor condensation, wetting and drying cycles on the interior surfaces of the chamber. Ultimately, the model enabled the authors to propose a favorable preservation method for the Takamatsuzuka Tumulus. The findings of this research show that:

The temperature difference of the whole protected object is the main reason influencing the drying and condensing process that occurred on the surfaces of mural paintings.

To preserve the mural paintings in the underground chamber, the temperature difference of the whole chamber should be kept to less than $4^{\circ} \mathrm{C}$.

A favourable method for the conservation of mural paintings in the Takamatsuzuka Tumulus is to cover the exposed stone chamber by a layer of thermal insulation material, positioned as shown in Fig.12. with thermal resistance of no less than $7.0\left[\mathrm{~m}^{2} \mathrm{~K} / \mathrm{W}\right]$.

\section{Acknowledgment}

This study was supported by JSPS (Japan Society for the Promotion of Science) KAKENHI (20560549), and NSF (National Science Foundation) of China (Grant No. 51108072 and Grant No. 51138002). The authors would like to thank Prof. Mark Bomberg for the discussions concerning the choice of the conservation methods.

\section{References}

1) Hejazi, M. (2008) The risks to cultural heritage in western and central Asia, Journal of Asian Architecture and Building Engineering, 7(2), pp.239-245.

2) Matsumiya, K; Oikawa, K. (2013) Quantitative Analysis of Fire Spreading Potential for Surrounding Areas of Cultural Properties in Kyoto City, Journal of Asian Architecture and Building Engineering, 12(2), pp.269-276.

3) Li, YH.; Xie, HR.; Wang JG.; Li XJ. (2013) Experimental Study of the Isothermal Sorption Properties of Late Qing and 1980s Grey Bricks in Wujiang, Suzhou, China. Frontiers of Architectural Research, 2(4), pp.483-487.

4) Shi X.; She W.; Zhou HL.; Zhan YS.; Shi F.; Chen W. (2012) Thermal upgrading of Hui-style vernacular dwellings in China using foam concrete. Frontiers of Architectural research, 1(1), pp.23-33.

5) Takatori, K., Takatori M., Kumeda Y., Kigawa R and Sano, C. (2010) Physiological and Biological Studies on the Growth of Fungi Isolated from Takamatsuzuka Tumulus (in Japanese), Science for Conservation, No. 49, pp.61-71.

6) Johansson, S., Wadsö, L., Sandin, K. (2010) Estimation of mould growth levels on rendered facades on surface relative humidity and surface temperature measurements, Building and Environment, 45(5), pp.1153-1160.

7) K. Sedlbauer. (2002) Prediction of mould growth by hygrothermal calculation, Journal of Building Physics, 25 (4), pp.321-336.

8) Gock, MA., Hocking, AD., Pitt, JI. and Poulos, PG. (2003) Influence of temperature, water activity and $\mathrm{pH}$ on growth of some xerophilic fungi, Source: International Journal of Food Microbiology, 81(1), pp.11-19.

9) Ogura D., Inuzuka M., Hokoi S., Ishizaki T., et al. (2008) Control of temperature and humidity surrounding the stone chamber of Takamatsuzuka Tumulus during its dismantlement, International Symposium on the Conservation and Restoration of Cultural Property, Tokyo, 2008, pp.75-81.

10) Li YH., Ogura D., Hokoi S., Ishizaki, T. (2012) Effects of emergency preservation measures following excavation of mural paintings in Takamatsuzuka Tumulus, Journal of Building Physics, 36 (2), pp.117-139.

11) Li YH., Ogura D., Hokoi S., Ishizaki, T. (2012) Numerical analysis of heat behavior of stone chamber after excavation, Frontiers of Architectural Research, Frontiers of Architectural Research, 1(4), pp.375-379.

12) Archaeological Institute of Kashihara (Nara prefecture, Japan) Edit, (1972) Survey interim report of mural painting in Takamatsuka Tumulus, (in Japanese), pp.20-23.

13) Matsumoto, M. (1978) Simultaneous heat and moisture transfer and moisture accumulation in building materials, Dissertation, Kyoto University, Kyoto (in Japanese).

14) Matsumoto M, Hokoi S, Hatano M. (2001) Model for simulation of freezing and thawing processes in building materials $[\mathrm{J}]$. Building and Environment, 36(6), pp.733-742.

15) Khalil, M. and Ishizaki, T. (2007). Moisture Characteristic Curves of the Soil of Takamatsuzuka Tumulus, Science for Conservation, No. 46, pp.13-20.

16) Khalil, M. and Ishizaki, T. (2008) Moisture Characteristic Curves of Tuff Breccia Stone, Science for Conservation, No. 47, pp.11-19. 
17) Ishizaki, T., Miura, S., Inuzuka, M. and Khalil, M. (2006) Examination and Choice of Cooling Methods for the Mound of Takamatsuzuka Tumulus as Protective Measures against Fungi in the Stone Chamber (in Japanese), Science for Conservation, No. 45, pp.59-68.

18) Ishizaki, T., Inuzuka, M. and Mimura, M. 2006. Study on Geotechnical Properties and Moisture Regime of Takamatsuzuka Tumulus (in Japanese), Science for Conservation, No. 45, pp.6976.

19) Kodai, K. 1984. The graph of base rock water permeability (in Japanese), Bulletin of the Geological Survey of Japan, 35(9), pp.419-434.

20) Japan Meteorological Business Support Center, Japan Meteorological Agency, (2007) Weather database ground observation, (CD-ROW).

21) Agency of Cultural Affairs. (1987) National Treasure Takamatsuzuka Tumulus Preservation and Maintenance (in Japanese), pp.36-38. 